\title{
Clemastine Enhances Myelination in the Prefrontal Cortex and Rescues Behavioral Changes in Socially Isolated Mice
}

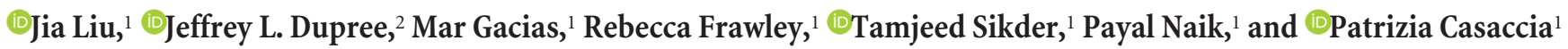 \\ ${ }^{1}$ Department of Neuroscience and Friedman Brain Institute, Icahn School of Medicine at Mount Sinai, New York, New York 10029, and 'Department of \\ Anatomy and Neurobiology, Virginia Commonwealth University, Richmond, Virginia 23298
}

\begin{abstract}
Altered myelin structure and oligodendrocyte function have been shown to correlate with cognitive and motor dysfunction and deficits in social behavior. We and others have previously demonstrated that social isolation in mice induced behavioral, transcriptional, and ultrastructural changes in oligodendrocytes of the prefrontal cortex (PFC). However, whether enhancing myelination and oligodendrocyte differentiation could be beneficial in reversing such changes remains unexplored. To test this hypothesis, we orally administered clemastine, an antimuscarinic compound that has been shown to enhance oligodendrocyte differentiation and myelination in vitro, for 2 weeks in adult mice following social isolation. Clemastine successfully reversed social avoidance behavior in mice undergoing prolonged social isolation. Impaired myelination was rescued by oral clemastine treatment, and was associated with enhanced oligodendrocyte progenitor differentiation and epigenetic changes. Clemastine induced higher levels of repressive histone methylation (H3K9me3), a marker for heterochromatin, in oligodendrocytes, but not neurons, of the PFC. This was consistent with the capability of clemastine in elevating $\mathrm{H} 3 \mathrm{~K} 9$ histone methyltransferases activity in cultured primary mouse oligodendrocytes, an effect that could be antagonized by cotreatment with muscarine. Our data suggest that promoting adult myelination is a potential strategy for reversing depressive-like social behavior.
\end{abstract}

Key words: depression; epigenetics; myelination; prefrontal cortex; social isolation

\section{Significance Statement}

Oligodendrocyte development and myelination are highly dynamic processes influenced by experience and neuronal activity. However, whether enhancing myelination and oligodendrocyte differentiation is beneficial to treat depressive-like behavior has been unexplored. Mice undergoing prolonged social isolation display impaired myelination in the prefrontal cortex. Clemastine, a Food and Drug Administration-approved antimuscarinic compound that has been shown to enhance myelination under demyelinating conditions, successfully reversed social avoidance behavior in adult socially isolated mice. This was associated with enhanced myelination and oligodendrocyte differentiation in the prefrontal cortex through epigenetic regulation. Thus, enhancing myelination may be a potential means of reversing depressive-like social behavior.

\section{Introduction}

A growing body of evidence has suggested that myelination and oligodendrocyte development are highly dynamic processes that continue into adult life. Myelination and oligodendrocytes, the

\footnotetext{
Received Sept. 28, 2015; revised Nov. 30, 2015; accepted Dec. 10, 2015.

Author contributions: J.L. and P.C. designed research; J.L., M.G., R.F., T.S., and P.N. performed research; J.L. and J.L.D. analyzed data; J.L. and P.C. wrote the paper.

This work was supported by the National Institute of Neurological Disorders and Stroke (2R37NS042925-10, R01NS52738 to P.C.) and by National Institutes of Health (NIH)-National Institute of Neurological Disorders and Stroke Center Core Grant 5 P30 NS047463 and NIH-National Cancer Institute Cancer Center Grant P30 CA016059 to J.L.D. We thank Drs. Eric Nestler, Scott Russo, Georgia Hodes, and Rosemary Bagot for the help with animal behavioral assessments. We thank Ms. Komal Keerthy for technical help. We apologize to our colleagues whose work we did not cite due to limited space.

The authors declare no competing financial interests.

Correspondence should be addressed to Jia Liu at the above address. E-mail: Jia.Liu@mssm.edu.

DOI:10.1523/JNEUROSCI.3608-15.2016

Copyright $\odot 2016$ the authors $\quad 0270-6474 / 16 / 360957-06 \$ 15.00 / 0$
}

myelin-forming cells of the CNS, respond to experience and neuronal activity, thereby contributing to physiological brain function and behavior (Sánchez et al., 1998; Liu et al., 2012; Makinodan et al., 2012; Gibson et al., 2014; McKenzie et al., 2014). Children suffering severe childhood neglect displayed reduced corpus callosum area (Teicher et al., 2004; Mehta et al., 2009). Social deprivation during the critical period of adolescence resulted in changes in oligodendrocyte gene expression, morphology, and myelin thickness in juvenile mice (Makinodan et al., 2012). Social isolation of adult mice resulted in reduced social interaction, a sign of depressive-like behavior, with downregulated oligodendroglial transcripts and myelin thickness in the prefrontal cortex (PFC; Liu et al., 2012), which has also been detected in brains of patients with major depressive disorders and schizophrenia (Tkachev et al., 2003; Aston et al., 2005; Katsel et al., 2005). Furthermore, impaired myelination in socially isolated 
adult mice preceded the onset of depressive-like behavior, and was associated with delayed oligodendrocyte progenitor differentiation, aberrant nuclear chromatin structure, and heterochromatic epigenetic changes (Liu et al., 2012). In addition, mice carrying a single copy of the oligodendrocyte-specific gene Cnp1, although characterized by normal myelin structure, showed catatonia and depressive-like behavior with aging (Hagemeyer et al., 2012), suggesting a role for oligodendrocytes in psychiatric illnesses.

Despite the wealth of knowledge linking impaired myelination and psychiatric disorders, little is known about the therapeutic potential of promoting oligodendrocyte generation, differentiation, and myelination for depressive behavior. In the context of learning, generation of new oligodendrocytes has been shown to be essential for mice to acquire motor skills, such as running on the complex wheel (McKenzie et al., 2014). Consistent with the concept that learning triggers neuronal activity changes, increased excitatory neuronal activity triggered by optogenetic stimulation in premotor cortex induced oligodendrocyte progenitor cell (OPC) proliferation and differentiation, and increased myelin thickness in mice, which led to improved motor function. The improvement was abolished when oligodendrogenesis and myelination were blocked by epigenetic modifiers (Gibson et al., 2014), suggesting that the enhanced myelination is necessary for improved motor skills.

Clemastine is a leading candidate for myelin formation, identified from a high-throughput screening using a library containing Food and Drug Administration-approved small compounds (Mei et al., 2014). It has been shown to promote OPC differentiation in vitro and remyelination after demyelinating lesions in mice (Deshmukh et al., 2013; Mei et al., 2014; Li et al., 2015). A recent study has shown a beneficial effect in restoring spatial working memory in mice treated with clemastine following 6 weeks of cuprizone diet, a diet that induces demyelination ( $\mathrm{Li}$ et al., 2015). Here we hypothesized that enhancing myelination could be beneficial for rescuing social withdrawal behavior in socially isolated mice. The effects of oral clemastine treatment in mice after 8 weeks of social isolation were assessed by social interaction and myelination in the PFC. We also examined epigenetic modifications in both neuron and oligodendrocyte populations and detected a specific effect of repressive histone methylation in oligodendrocytes, but not neurons, by clemastine treatment. The study below suggests a positive effect of enhanced myelination and oligodendrocyte differentiation in reversing depressive-like behavior in adult mice.

\section{Materials and Methods}

Social isolation and drug treatment. All experimental C57BL/6J male mice were obtained from the Jackson Laboratory and maintained in a temperature-controlled and humidity-controlled facility on a $12 \mathrm{~h}$ light/ dark cycle with food and water available ad libitum. All procedures were performed in accordance with the Institutional Animal Care and Use Committee guidelines of the Icahn School of Medicine at Mount Sinai. Adult mice ( 8 weeks old) were either singly housed or group housed (five mice per cage) for 10 weeks. For the drug treatment, isolated mice were given vehicle double-distilled $\mathrm{H}_{2} \mathrm{O}\left(\mathrm{dd}_{2} \mathrm{O}\right)$ or clemastine (dissolved in $\mathrm{ddH}_{2} \mathrm{O}, 10 \mathrm{mg} \mathrm{kg}^{-1}$ body weight; Tocris Bioscience) daily through gastric gavaging for the last 2 weeks (Fig. 1A).

Social interaction test. Social interaction behavior was assessed as previously described (Liu et al., 2012) at the end of the eighth and tenth weeks, respectively. A one-way ANOVA test was performed to assess statistical differences.

RNA tissue extraction and analysis. Tissue punches were taken from the $\mathrm{PFC}$ and flash frozen for subsequent processing. RNA extraction, reverse
A

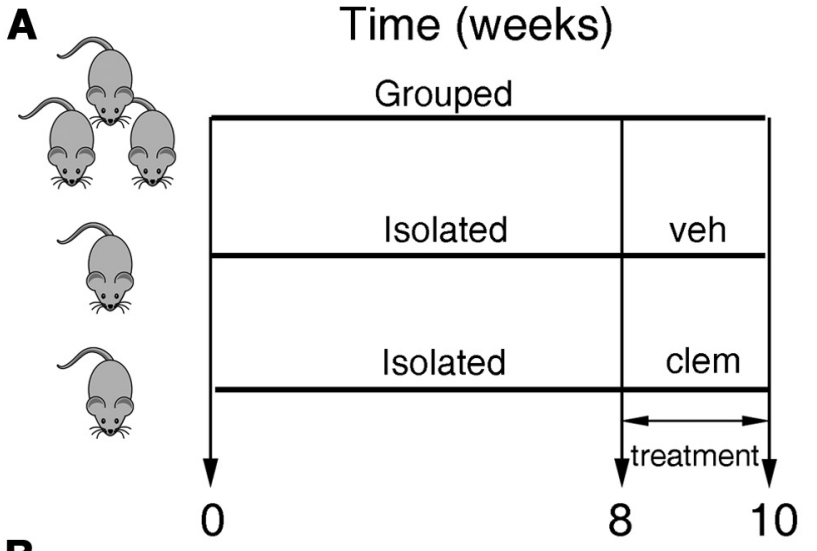

B

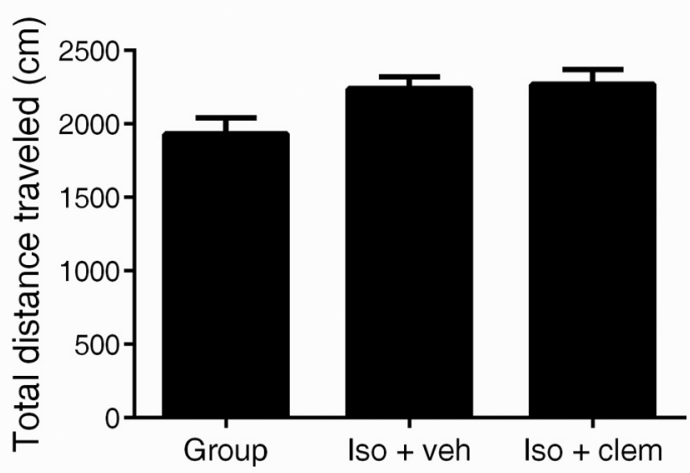

C

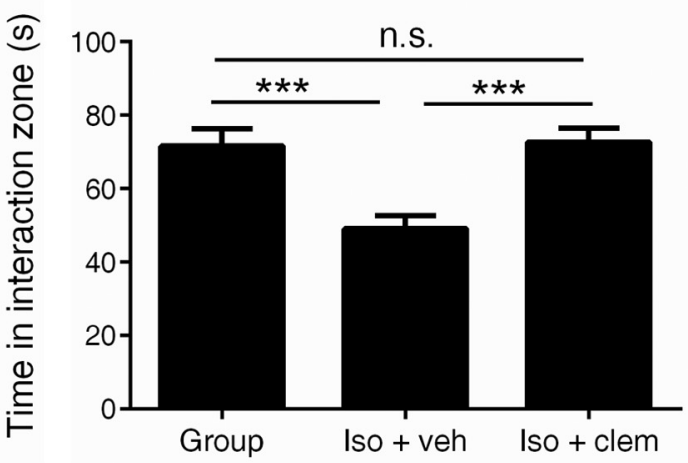

Figure 1. Clemastine rescues social avoidance behavior in socially isolated mice. $\boldsymbol{A}$, Experimental scheme. Adult mice were group-housed for 10 weeks or isolated for 8 weeks followed by daily treatment of vehicle ( $\mathrm{ddH}_{2} \mathrm{O}$ ) or clemastine (gastric gavage, $10 \mathrm{mg} \mathrm{kg}^{-1}$ body weight) for 2 weeks. Mice were tested for social interaction behavior at the end of 10 weeks. $\boldsymbol{B}$, Clemastine (clem) did not affect locomotor activity of socially isolated mice. $\boldsymbol{C}$, Clemastine rescued time spent with a conspecific mouse of socially isolated mice $[n=25$ for group-housed (group), $n=21$ for iso + veh, $n=19$ for iso + clem]. ${ }^{* * *} p<0.001$ by one-way ANOVA followed by Tukey's post hoc test. n.s., Not significant. Data are mean \pm SEM.

transcription, and qRT-PCR were performed as previously described (primers listed in Liu et al., 2012). The average values for each transcript was calculated after normalization to Gapdh and 18s. A two-way ANOVA test was performed to assess statistical differences.

Electron microscopy. Mice were processed for standard electron microscopy (EM) analysis as previously described (Liu et al., 2012). Briefly, the PFC was isolated and mounted for $1 \mu \mathrm{m}$ sectioning, followed by staining with toluidine and imaged at $1000 \times$ using an AxioImager A1 Zeiss microscope with a $100 \times$ oil-objective lens with a numerical aperture of 1.4. Image collection was restricted to layers 4-6. Numbers of myelinated axons were quantified in each field of view (FOV), which consists of $15,105 \mu \mathrm{m}^{2}$. For EM, the mounted section was trimmed to encompass a $\sim 1 \mu \mathrm{m}^{2}$ region of layers $4-6$ of the PFC, thin sectioned at $90 \mathrm{~nm}$, stained with uranyl acetate and lead citrate, and mounted on 200 
mesh copper grids. Ten images at 10,000× were collected per mouse using a JEOL transmission electron microscope equipped with a Gatan CCD camera. $g$ ratios were determined by dividing the diameter of the axon by the diameter of the entire myelinated fiber. ImageJ was used to measure both axon caliber and myelin fiber diameter for a minimum of 100 myelinated axons per mouse. All analyses were performed blind to the experimental conditions. One-way ANOVA tests were performed to assess statistical differences.

Immunohistochemistry. Mice were anesthetized and then perfused, cryopreserved, embedded, and sectioned as previously described (Liu et al., 2012). Immunohistochemistry was performed as previously described (Liu et al., 2012) with primary antibodies trimethylated histone 3 lysine 9 (H3K9me3, 1:100; ab8898, Abcam), CC1 (1:100; OP80, EMD Millipore), NeuN (1:400; MAB377, EMD Millipore), myelin basic protein (MBP, 1:500; SMI99, Covance), or NG2 (1:200; AB5320, EMD Millipore). Stained sections were visualized using confocal microscopy (LSM710 Meta confocal laser scanning microscope, Carl Zeiss MicroImaging). For NG2, CC1 cell counts, and $\mathrm{H} 3 \mathrm{~K} 9$ me3 quantifications, 4-6 fields were taken per mouse. For MBP area quantification, four $20 \times$ fields were taken per mouse. Two or three mice were included per treatment condition. $\mathrm{MBP}+$ area and pixel intensity of $\mathrm{H} 3 \mathrm{~K} 9 \mathrm{me} 3$ were quantified using ImageJ. One-way ANOVA tests were performed to assess statistical differences.

Cell culture and treatment. Oligodendrocyte progenitors were isolated from postnatal day (P) 6-P8 C57BL/6 mice of either sex and cultured as previously described (Liu et al., 2015). Cultures were maintained under proliferating conditions by adding PDGF (10 ng/ml) and bFGF (20 ng/ $\mathrm{ml})$. For drug treatment, cultures were treated in the absence of mitogen.

MTT assay. The MTT [3-(4,5-dimethyl-2-thiazolyl)-2,5-diphenyltetrazolium bromide; Sigma-Aldrich] solution was prepared in PBS and added to cells in culture at a final concentration of $0.5 \mathrm{mg} / \mathrm{ml}$, and incubated for $4 \mathrm{~h}$ at $37^{\circ} \mathrm{C}$. The quantity of formazan was dissolved in DMSO and measured by recording changes in absorbance at $540 \mathrm{~nm}$ using a plate reading spectrophotometer.

Histone methyltransferase activity assay. Fresh nuclear extracts were isolated from OPC cultures maintained in either proliferating conditions or differentiating conditions [i.e., $45 \mathrm{~nm}$ T3 hormone (Sigma-Aldrich), or $1 \mu \mathrm{M}$ clemastine with or without $100 \mu \mathrm{M}$ muscarine (Tocris Bioscience)] for $3 \mathrm{~d}$ in vitro using a nuclear extraction kit (Active Motif). Histone methyltransferase activity was measured using an H3K9 methyltransferase activity kit (Epigentek) following manufacturer's protocol with fresh nuclear extracts.

\section{Results}

\section{Clemastine treatment rescues social avoidance behavior in adult mice}

The current study was designed to test the hypothesis that promoting myelin formation in the adult brain is beneficial in reversing depressive-like behavior. To test this hypothesis, we administered clemastine after mice were socially isolated for 8 weeks to induce social avoidance behavior (Fig. 1A). Mice were then treated with clemastine for 2 weeks while continuing to be housed in isolation. The control group consisted of grouphoused mice. After clemastine treatment, we did not detect any difference in locomotion among group-housed controls, isolated mice treated with vehicle (iso + veh), and isolated mice treated with clemastine (iso + clem; traveled distance: $1932 \pm 109 \mathrm{~cm}$ in controls, $2223 \pm 81 \mathrm{~cm}$ in iso $+\mathrm{veh}$, and $2269 \pm 101 \mathrm{~cm}$ in iso + clem, average \pm SEM; Fig. $1 B)$. However, while the isolated mice treated with vehicle continued to show signs of social withdrawal (interaction time with a conspecific mouse: $49.1 \pm 3.6 \mathrm{~s}$, average \pm SEM), statistically different from group-housed peers $(71.7 \pm 4.6 \mathrm{~s}$, average $\pm \mathrm{SEM}, p=0.0006)$, isolated mice treated with clemastine were indistinguishable $(72.7 \pm 3.8 \mathrm{~s}$, average \pm SEM) from the group-housed controls (Fig. 1C). These results indicate that clemastine treatment was sufficient to reverse the social withdrawal behavior in socially isolated mice.

\section{Clemastine enhances myelination and oligodendrocyte differentiation in the PFC}

To determine whether the reversed social behavior in clemastinetreated mice was due to changes in myelination, we examined myelin at transcript, protein, and ultrastructure levels. We focused our analysis on the PFC, as this is a region that is functionally relevant to the control of social behavior and the only region that displayed impaired myelination in socially isolated mice compared with other brain regions (i.e., nucleus accumbens, corpus callosum, and cerebellum) from our previous study (Liu et al., 2012). We detected a trend toward increased myelin gene transcripts in clemastine-treated mice compared with vehicletreated ones (Fig. 2A), although it did not reach statistical significance ( $n=4$ group-housed, $n=4$ iso + veh, and $n=6$ iso + clem), likely because harvesting occurred after myelin proteins were already expressed and thereby with minimal residual transcriptional changes. However, immunohistochemical analysis revealed significant differences in the percentage of $\mathrm{MBP}+$ myelinated fibers between the vehicle-treated $(16.2 \pm 1.7 \%)$ and group-housed mice $(27.5 \pm 3.4 \%, p=0.0025)$, while mice treated with clemastine $(23.3 \pm 1.3 \%, p=0.0382$ compared with iso + veh) were similar to the control groups (Fig. $2 B, C$ ). Analysis using semithin sections of the PFC provided further evidence that clemastine treatment resulted in significantly more myelinated axons $(570.8 \pm 31.3 / \mathrm{FOV})$ compared with vehicle-treated isolated mice $(422.1 \pm 37.0 / \mathrm{FOV}, p=0.0244$ compared with iso + clem), thereby restoring the number of myelinated fibers to control values (group-housed: $531.7 \pm 45.8 / \mathrm{FOV}$, average \pm SEM; Fig. 2D). Ultrastructural analysis revealed a restoration of myelin thickness in the PFC of isolated mice treated with clemastine to levels comparable to group-housed controls (Fig. 2E). Quantification of myelin thickness relative to axonal diameter ( $g$ ratio) revealed that social isolation resulted in thinner myelin in mice treated with vehicle $(g=0.882 \pm 0.003)$, compared with group-housed peers $(g=0.851 \pm 0.004, p<0.0001)$. This was reversed when isolated mice were treated with clemastine ( $g=$ $0.854 \pm 0.004, p<0.0001$; Fig. $2 F)$. No significant difference was detected between group-housed mice and isolated mice treated with clemastine. Therefore, clemastine restored myelination defect in the PFC induced by social isolation.

The enhanced myelination by clemastine could be due to increased OPC proliferation or differentiation, or a combination of both. To distinguish among these possibilities, we analyzed OPC and mature oligodendrocyte populations in the PFC by immunohistochemistry. Immunostaining of NG2, a marker for OPCs, revealed significantly increased number of progenitors in isolated mice treated with vehicle (cells $/ \mathrm{mm}^{2}: 72.5 \pm 11.9$ ) compared with group-housed ones (cells/ $\mathrm{mm}^{2}: 29.8 \pm 4.3, p<0.05$; Fig. $2 G, H)$. This was consistent with our previous findings where a lower percentage of heterochromatin, a differentiation marker of OPC, was detected in the PFC of socially isolated mice (Liu et al., 2012). No significant difference was detected between isolated mice treated with clemastine (cells $/ \mathrm{mm}^{2}: 49.4 \pm 7.2$ ) and grouphoused controls, suggesting that clemastine did not significantly modulate OPC proliferation. In contrast, we identified a significant increase of $\mathrm{CC} 1+$ cells, a marker for mature oligodendrocytes, in the PFC of clemastine-treated mice (cells $/ \mathrm{mm}^{2}: 91.1 \pm$ 9.9) compared with vehicle-treated controls (cells/ $\mathrm{mm}^{2}: 57.0 \pm$ $8.5, p<0.05$; Fig. $2 I, J)$. We conclude that the enhanced myelination by clemastine is resulted from increased OPC differentiation, but not proliferation. 


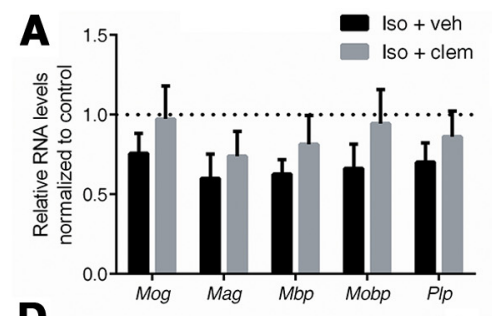

D
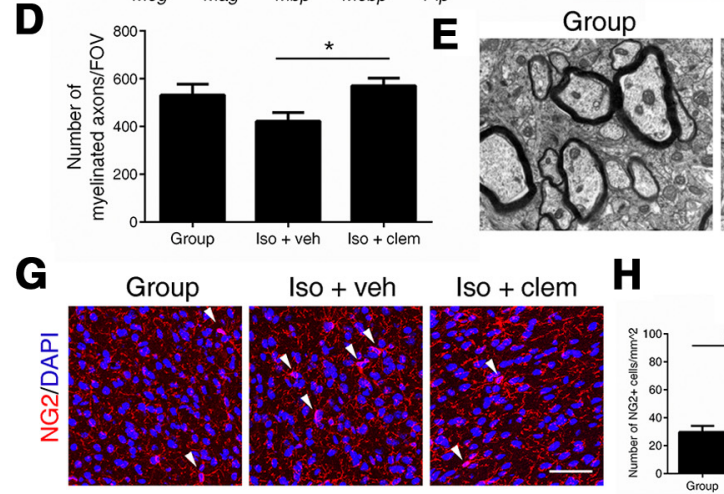

B

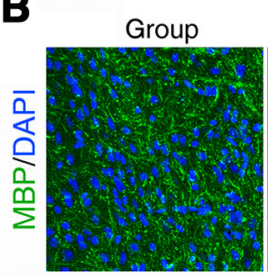

Iso + veh

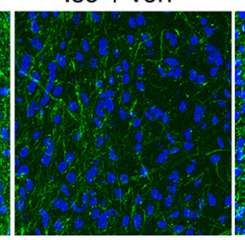

Iso + veh
Iso + clem

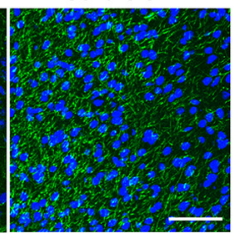

Iso + clem
C

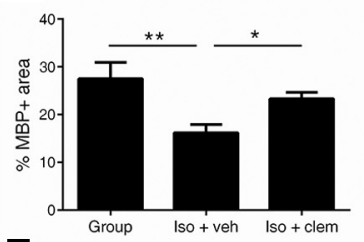

$\mathbf{F}$

1.0
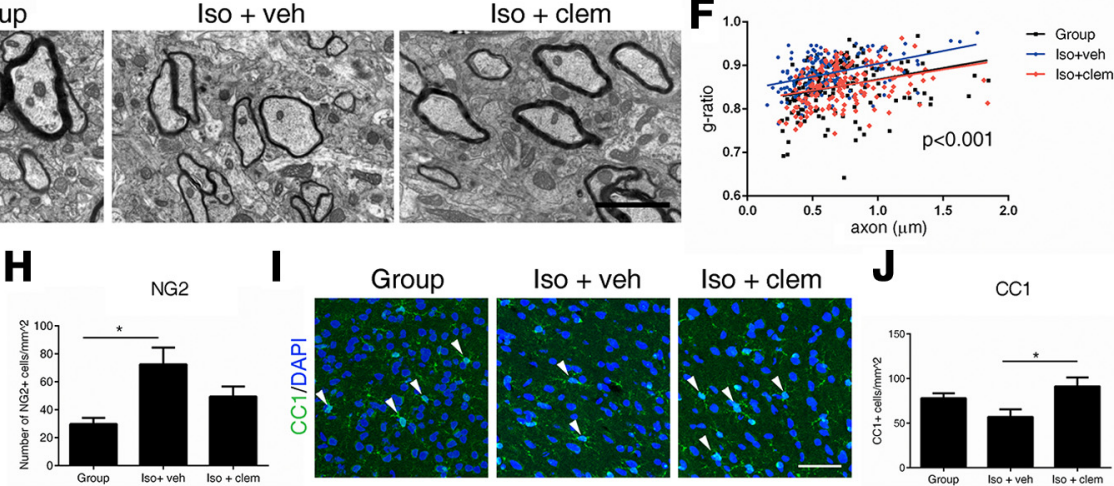

J

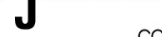

Figure 2. Clemastine enhances myelination and oligodendrocyte differentiation in the PFC. $A$, Quantitative real-time PCR (qRT-PCR) of myelin gene transcripts in the PFC. Bar graphs indicate average values in isolated mice ( $n=4$ iso + veh, $n=6$ iso + clem) after Gapdh and 18 s normalization relative to average levels in group-housed mice ( $n=4$; dashed line). $\boldsymbol{B}, \boldsymbol{C}$, Confocal images and quantifications of MBP + (green) myelinated fibers in PFC. DAPI (blue) was used as nuclear counterstain. Scale bar, $50 \mu \mathrm{m} .{ }^{*} p<0.05,{ }^{* *} p<0.01$ by one-way ANOVA followed by Tukey's post hoc test, $n=12$ fields from 3 mice per treatment condition. D, Quantification of myelinated axons per FOV in PFC using semithin transverse sections from group-housed (Group), iso + veh, and iso + clem mice. $n=18$ fields from 3 mice per treatment condition. * $p<0.05$ by one-way ANOVA followed by Tukey's post hoc test. $\boldsymbol{E}$, EMs of axons in PFC from group-housed (Group), iso + veh, and iso + clem mice. Scale bar, $2 \mu \mathrm{m}$. $\boldsymbol{F}$, Scatter plot of $g$-ratio values in the PFC in group-housed (Group; $n=183$ axons), iso + veh ( $n=154$ axons), and iso + clem ( $n=159$ axons) mice. $p<$ 0.0001 for group versus is $0+$ veh; $p<0.0001$ for is + veh versus is $0+$ clem; by one-way ANOVA followed by Tukey's post hoc test. $n=30$ fields from 3 mice per treatment condition. $\mathbf{G}, \boldsymbol{H}$, Confocal images and quantifications of NG2 + (red) cells in PFC. DAPI (blue) was used as nuclear counterstain. Scale bar, $50 \mu \mathrm{m}$. I-J, Confocal images and quantifications of CC $1+$ cells in PFC. ${ }^{*} p<0.05$ by one-way ANOVA followed by Tukey's post hoc test. Data are mean \pm SEM.

\section{Clemastine increases repressive histone methylation in oligodendrocytes, but not neurons, of the PFC}

Because chromatin compaction positively correlates with the maturation stage of oligodendrocytes (Liu et al., 2012) and repressive histone methylation is necessary for the progression of the differentiation stage (Liu et al., 2015), we examined population-level changes in a repressive histone modification, H3K9me3 (indicative of heterochromatin state; Fig. $3 A-D$ ). Social isolation significantly decreased levels of $\mathrm{H} 3 \mathrm{~K} 9 \mathrm{me} 3 \mathrm{immu}-$ noreactivity in $\mathrm{CC} 1+$ oligodendrocytes (pixel/area: $1702 \pm 12$, $n=143$ cells from 3 iso + veh mice), compared with grouphoused mice (pixel/area: $2288 \pm 70, n=167$ cells from 2 grouphoused mice, $p<0.001)$. This was reversed when mice were treated with clemastine (pixel/area: $2687 \pm 16, n=258$ cells from 3 iso + clem mice, $p<0.001$; Fig. $3 A, C$ ). The levels of H3K9me3 in oligodendrocytes of clemastine-treated mice were even higher than those for group-housed controls $(p<0.001)$, suggesting a very potent effect of clemastine in inducing repressive histone methylation (Fig. 3C). In contrast, despite the systemic administration of the drug, we did not detect any changes in the NeuN+ neuronal population (Fig. $3 B, D$ ), as levels of repressive histone methylation (i.e., H3K9me3) were unaffected by housing or treatment conditions in PFC neurons.

Finally, we asked whether the enzymatic activities of the H3K9 histone methyltransferases (HMTs) were directly modulated in cultured oligodendrocytes exposed to clemastine and its antagonist, muscarine. A dose-response analysis of toxicity was performed in primary mouse OPC cultures using an MTT assay (Fig. $3 E, F)$. As control for prodifferentiating factors, we used thyroid hormone (T3, $45 \mathrm{nM}$ ), which induced a significant increase of H3K9 HMT activity (fold change: $8.2 \pm 1.5$, average \pm SEM, $p=$ $0.0287)$. Clemastine $(1 \mu \mathrm{M})$ treatment further increased levels of
H3K9 HMT activity [fold change: $17.3 \pm 2.8$, average \pm SEM, $p<0.0001$ compared with cells treated with PDGF A chain homodimer and bFGF (P/F), $p=0.0038$ compared with T3; Fig. $3 G]$. Such augmentation was significantly attenuated when cells were cotreated with the antagonist muscarine $(100 \mu \mathrm{M})$ at nontoxic doses (fold change: $7.5 \pm 1.2, p=0.0018$ compared with clemastine; Fig. $3 G$ ). Therefore, clemastine induces OPC differentiation possibly by enhancing the activity of HMTs and favoring chromatin compaction.

\section{Discussion}

Here we reported that enhanced myelination and OPC differentiation are beneficial for reversing depressive-like behavior in adult mice. Clemastine successfully enhanced myelination and OPC differentiation, and was sufficient to rescue social avoidance behavior in socially isolated mice. Clemastine and other muscarinic antagonists have been recently identified from drug-screening assays to promote OPC differentiation and myelination (Deshmukh et al., 2013; Mei et al., 2014; Li et al., 2015), although the underlying mechanism remains undefined. Subtypes of muscarinic receptors have been shown to be expressed in OPCs and mature oligodendrocytes (De Angelis et al., 2012). One possibility is that clemastine directly acts on these receptors in OPCs by favoring chromatin compaction, which has been shown to play a critical role in OPC lineage progression (Liu et al., 2012, 2015). In fact, clemastine is capable of promoting OPC differentiation (Mei et al., 2014) and activating H3K9 HMTs in cultured primary oligodendrocytes (Fig. 3) in the absence of neuronal or astrocytic signals. Levels of $\mathrm{H} 3 \mathrm{~K} 9 \mathrm{me} 3$, the outcome of activated HMTs, were specifically enhanced in oligodendrocytes, but not neurons, in the PFC of socially isolated mice, thereby supporting a direct and cell-autonomous effect 
A

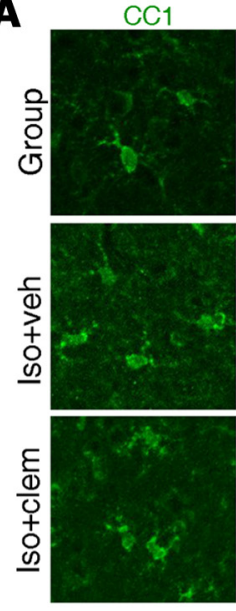

E

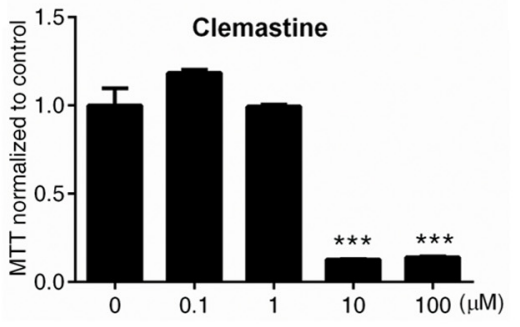

H3K9me3
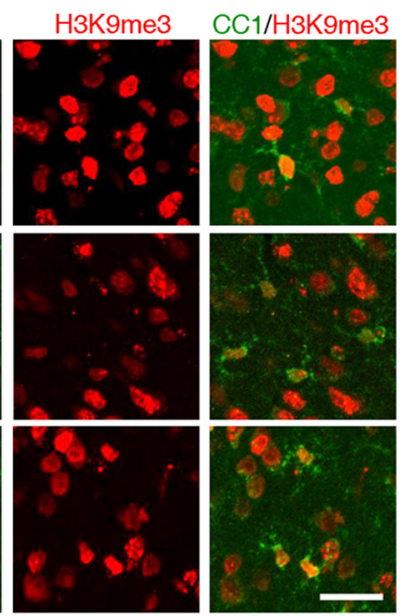

$\mathbf{F}$

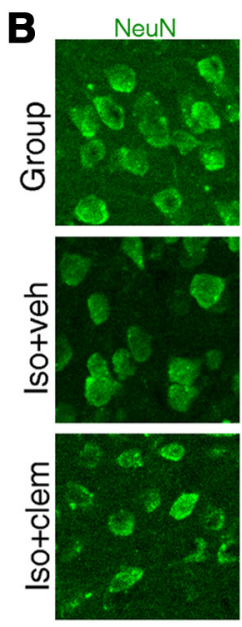

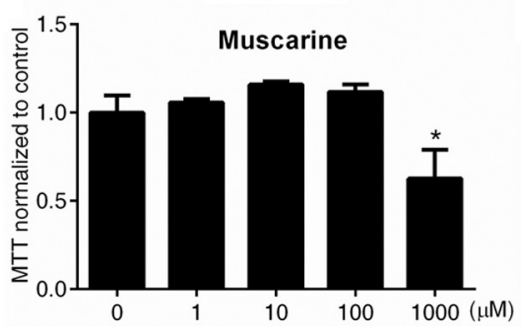
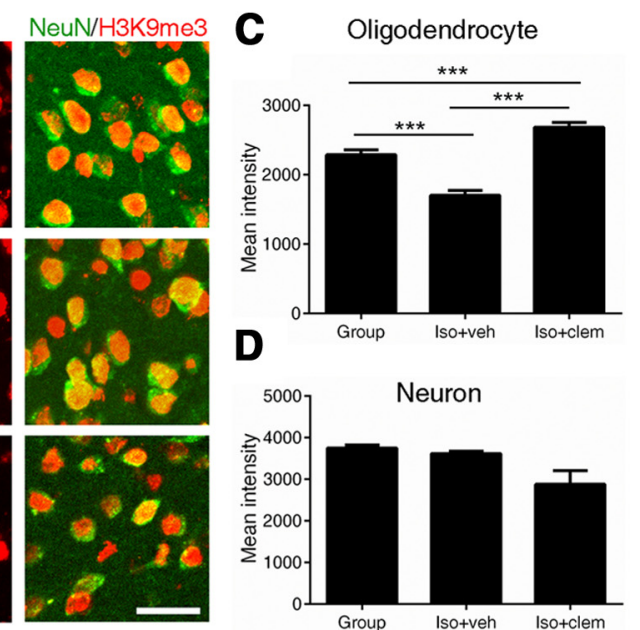

D

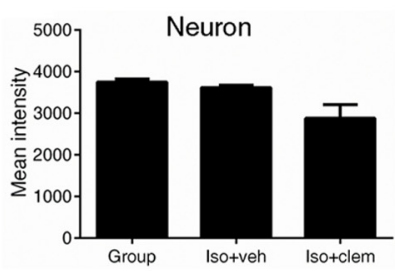

G

Figure 3. Clemastine increases levels of repressive histone modification H3K9me3 in oligodendrocytes. $\boldsymbol{A}, \boldsymbol{B}, \mathrm{Confocal}$ images of H3K9me3 (red) and CC1+ (green) oligodendrocytes $(\boldsymbol{A})$ or NeuN + (green) neurons (B) in PFC of group-housed (Group), iso + veh, and iso + clem mice. Scale bar, $25 \mu \mathrm{m}$. $\boldsymbol{C}$, Quantifications of H3K9me3 immunoreactivity in CC1+ oligodendrocytes in the PFC $[n=167$ cells from 2 group-housed (Group) mice, $n=143$ cells from 3 iso + veh mice, and $n=258$ cells from 3 iso + clem mice $]$. ${ }^{* * *} p<0.001$ by one-way ANOVA followed by Tukey's post hoc test. D, Quantifications of H3K9me3 immunoreactivity in NeuN + neurons in the PFC ( $n=293$ cells from 2 group-housed (Group) mice, $n=436$ cells from 3 iso + veh mice, $n=411$ cells from 3 iso + clem mice). $\boldsymbol{E}, \boldsymbol{F}$, The dose-dependent toxicity of clemastine $(\boldsymbol{E})$ and muscarine $(\boldsymbol{F})$ was assessed in primary mouse oligodendrocyte cultures, using MTT assays. G, H3K9 methyltransferase activity increased when OPCs were treated for $72 \mathrm{~h}$ with thyroid hormone (T3, $45 \mathrm{~nm}$ ) or clemastine (1 $\mu \mathrm{m}$ ) compared with mitogens PDGF A chain homodimer and bFGF (P/F). The increase of H3K9 methyltransferase activity by clemastine was attenuated when $0 \mathrm{PC} s$ were cotreated with clemastine (1 $\mu \mathrm{m}$ ) and muscarine $(100 \mu \mathrm{m})$. Fold changes were calculated after normalizing to activity in proliferating condition (P/F). $n=3$ separate cultures per condition. ${ }^{*} p<0.05,{ }^{* *} p<0.005,{ }^{* * *} p<0.001$ by one-way ANOVA followed by Tukey's post hoc test. Data are mean \pm SEM.

on oligodendrocyte differentiation. A potentially alternative mechanism of action of clemastine, as a muscarinic receptor antagonist, was suggested by the activation of Akt/mammalian target of rapamycin (mTOR) pathways induced in synaptoneurosomes by scopolamine, a nonselective muscarinic antagonist (Voleti et al., 2013; Navarria et al., 2015). The Akt/mTOR pathway is a well characterized positive regulator of oligodendrocyte differentiation and myelination (Wood et al., 2013; Wahl et al., 2014). Therefore, similar signaling pathways could be activated in oligodendrocytes following clemastine treatment, which directly results in OPC differentiation and myelination.

Lack of social experience has been shown to induce impaired myelination in the PFC of juvenile and adult mice (Liu et al., 2012; Makinodan et al., 2012). It is widely accepted that exposure to stress in rodents altered neuronal activity in the PFC and resulted in depressive-like behavior (Covington et al., 2005, 2010; Veeraiah et al., 2014). Selective activation of neurons in PFC through optogenetic stimulation provided an antidepressant effect in a mouse model of depression (Covington et al., 2010). Increased neuronal activity through optogenetic manipulation in the mouse premotor cortex has been shown to promote myelination and oligodendrogenesis (Gibson et al., 2014). Therefore, a potential explanation for the impaired myelination detected in socially isolated mice could be diminished neuronal activity in the PFC. Here we demonstrated that clemastine-induced adult myelination is sufficient to rescue the depressive-like behavior in socially isolated rodents, thereby potentially overcoming the lack of activity of specific circuitry involving PFC and consequent behavioral deficits. However, one caution should be made when interpreting our results as we cannot exclude the possibility that clemastine-induced myelination and OPC differentiation could be a secondary effect of the drug on the neuronal circuitry. Systemic as well as local infusion of scopolamine had been previously shown to increase neuronal activity in the PFC by altering glutamate transmission and provided an antidepressant effect in the forced swim test of mice (Voleti et al., 2013; Navarria et al., 2015). Therefore, although specific PFC circuitry was not activated by "exogenous" social stimuli, neuronal activity could be altered through clemastine uptake, which in turn resulted in myelination enhancement. The precise mechanism of clemastine-mediated enhanced myelination and OPC differentiation in our model remains to be identified.

In summary, we propose that enhancing oligodendrocyte differentiation and myelination in the adult brain contributes to reverse depressive-like behaviors in mice. Thus, our findings provide a new insight into the role of myelination and oligodendrocyte function in modulating emotional behavior, and might be helpful for designing novel strategies to ameliorate psychiatric symptoms in mental disorders. 


\section{References}

Aston C, Jiang L, Sokolov BP (2005) Transcriptional profiling reveals evidence for signaling and oligodendroglial abnormalities in the temporal cortex from patients with major depressive disorder. Mol Psychiatry 10: 309-322. CrossRef Medline

Covington HE 3rd, Kikusui T, Goodhue J, Nikulina EM, Hammer RP Jr, Miczek KA (2005) Brief social defeat stress: long lasting effects on cocaine taking during a binge and zif268 mRNA expression in the amygdala and prefrontal cortex. Neuropsychopharmacology 30:310-321. CrossRef Medline

Covington HE 3rd, Lobo MK, Maze I, Vialou V, Hyman JM, Zaman S, LaPlant Q, Mouzon E, Ghose S, Tamminga CA, Neve RL, Deisseroth K, Nestler EJ (2010) Antidepressant effect of optogenetic stimulation of the medial prefrontal cortex. J Neurosci 30:16082-16090. CrossRef Medline

De Angelis F, Bernardo A, Magnaghi V, Minghetti L, Tata AM (2012) Muscarinic receptor subtypes as potential targets to modulate oligodendrocyte progenitor survival, proliferation, and differentiation. Dev Neurobiol 72:713-728. CrossRef Medline

Deshmukh VA, Tardif V, Lyssiotis CA, Green CC, Kerman B, Kim HJ, Padmanabhan K, Swoboda JG, Ahmad I, Kondo T, Gage FH, Theofilopoulos AN, Lawson BR, Schultz PG, Lairson LL (2013) A regenerative approach to the treatment of multiple sclerosis. Nature 502:327-332. CrossRef Medline

Gibson EM, Purger D, Mount CW, Goldstein AK, Lin GL, Wood LS, Inema I, Miller SE, Bieri G, Zuchero JB, Barres BA, Woo PJ, Vogel H, Monje M (2014) Neuronal activity promotes oligodendrogenesis and adaptive myelination in the mammalian brain. Science 344:1252304. CrossRef Medline

Hagemeyer N, Goebbels S, Papiol S, Kästner A, Hofer S, Begemann M, Gerwig UC, Boretius S, Wieser GL, Ronnenberg A, Gurvich A, Heckers SH, Frahm J, Nave KA, Ehrenreich H (2012) A myelin gene causative of a catatonia-depression syndrome upon aging. EMBO Mol Med 4:528-539. CrossRef Medline

Katsel P, Davis KL, Haroutunian V (2005) Variations in myelin and oligodendrocyte-related gene expression across multiple brain regions in schizophrenia: a gene ontology study. Schizophr Res 79:157-173. CrossRef Medline

Li Z, He Y, Fan S, Sun B (2015) Clemastine rescues behavioral changes and enhances remyelination in the cuprizone mouse model of demyelination. Neurosci Bull 31:617-625. CrossRef Medline

Liu J, Dietz K, DeLoyht JM, Pedre X, Kelkar D, Kaur J, Vialou V, Lobo MK, Dietz DM, Nestler EJ, Dupree J, Casaccia P (2012) Impaired adult myelination in the prefrontal cortex of socially isolated mice. Nat Neurosci 15:1621-1623. CrossRef Medline

Liu J, Magri L, Zhang F, Marsh NO, Albrecht S, Huynh JL, Kaur J, Kuhlmann T, Zhang W, Slesinger PA, Casaccia P (2015) Chromatin landscape defined by repressive histone methylation during oligodendrocyte differentiation. J Neurosci 35:352-365. CrossRef Medline

Makinodan M, Rosen KM, Ito S, Corfas G (2012) A critical period for social experience-dependent oligodendrocyte maturation and myelination. Science 337:1357-1360. CrossRef Medline

McKenzie IA, Ohayon D, Li H, de Faria JP, Emery B, Tohyama K, Richardson WD (2014) Motor skill learning requires active central myelination. Science 346:318-322. CrossRef Medline

Mehta MA, Golembo NI, Nosarti C, Colvert E, Mota A, Williams SC, Rutter M, Sonuga-Barke EJ (2009) Amygdala, hippocampal and corpus callosum size following severe early institutional deprivation: the English and Romanian adoptees study pilot. J Child Psychol Psychiatry 50:943-951. CrossRef Medline

Mei F, Fancy SP, Shen YA, Niu J, Zhao C, Presley B, Miao E, Lee S, Mayoral SR, Redmond SA, Etxeberria A, Xiao L, Franklin RJ, Green A, Hauser SL, Chan JR (2014) Micropillar arrays as a high-throughput screening platform for therapeutics in multiple sclerosis. Nat Med 20:954-960. CrossRef Medline

Navarria A, Wohleb ES, Voleti B, Ota KT, Dutheil S, Lepack AE, Dwyer JM, Fuchikami M, Becker A, Drago F, Duman RS (2015) Rapid antidepressant actions of scopolamine: role of medial prefrontal cortex and M1subtype muscarinic acetylcholine receptors. Neurobiol Dis 82:254-261. CrossRef Medline

Sánchez MM, Hearn EF, Do D, Rilling JK, Herndon JG (1998) Differential rearing affects corpus callosum size and cognitive function of rhesus monkeys. Brain Res 812:38-49. CrossRef Medline

Teicher MH, Dumont NL, Ito Y, Vaituzis C, Giedd JN, Andersen SL (2004) Childhood neglect is associated with reduced corpus callosum area. Biol Psychiatry 56:80 - 85. CrossRef Medline

Tkachev D, Mimmack ML, Ryan MM, Wayland M, Freeman T, Jones PB, Starkey M, Webster MJ, Yolken RH, Bahn S (2003) Oligodendrocyte dysfunction in schizophrenia and bipolar disorder. Lancet 362:798-805. CrossRef Medline

Veeraiah P, Noronha JM, Maitra S, Bagga P, Khandelwal N, Chakravarty S, Kumar A, Patel AB (2014) Dysfunctional glutamatergic and gammaaminobutyric acidergic activities in prefrontal cortex of mice in social defeat model of depression. Biol Psychiatry 76:231-238. CrossRef Medline

Voleti B, Navarria A, Liu RJ, Banasr M, Li N, Terwilliger R, Sanacora G, Eid T, Aghajanian G, Duman RS (2013) Scopolamine rapidly increases mammalian target of rapamycin complex 1 signaling, synaptogenesis, and antidepressant behavioral responses. Biol Psychiatry 74:742-749. CrossRef Medline

Wahl SE, McLane LE, Bercury KK, Macklin WB, Wood TL (2014) Mammalian target of rapamycin promotes oligodendrocyte differentiation, initiation and extent of CNS myelination. J Neurosci 34:4453-4465. CrossRef Medline

Wood TL, Bercury KK, Cifelli SE, Mursch LE, Min J, Dai J, Macklin WB (2013) mTOR: a link from the extracellular milieu to transcriptional regulation of oligodendrocyte development. ASN Neuro 5:e00108. CrossRef Medline 